ECCOMAS

Proceedia
COMPDYN 2021

$8^{\text {th }}$ ECCOMAS Thematic Conference on Computational Methods in Structural Dynamics and Earthquake Engineering M. Papadrakakis, M. Fragiadakis (eds.) Streamed from Athens, Greece, 28 - 30 June 2021

\title{
ON THE USE OF DIGITAL TWINS FOR SEISMIC STRUCTURAL HEALTH MONITORING OF A MONUMENTAL MASONRY TOWER
}

\author{
A. Kita ${ }^{1}$, N. Cavalagli ${ }^{1}$, I. Venanzi ${ }^{1}$ and F. Ubertini ${ }^{1}$ \\ ${ }^{1}$ Department of Civil and Environmental Engineering, University of Perugia \\ Via G. Duranti 93, 06125 Perugia, Italy \\ e-mail: \{alban.kita, nicola.cavalagli, ilaria.venanzi, filippo.ubertini\}@unipg.it
}

\begin{abstract}
This paper presents the introduction of Digital Twins in the case of an historic masonry tower for rapidly addressing earthquake-induced damage identification. In the context of the present paper, a digital twin is a model or a suite of models of the considered structure that are updated/modified during time based on monitoring data. In particular, the proposed approach combines Operational Modal Analysis (OMA), Surrogate Modeling (SM) and nonlinear Incremental Dynamic Analysis (IDA). On the one hand, OMA-based Structural Health Monitoring (SHM) systems successfully allow the detection of small structural damages occurring during earthquakes, and on the other, SM exploits the correlation between continuous vibration data and structural stiffnesses while IDA is carried out from a tuned model together with in situ recorded seismic data. The San Pietro bell tower has been considered for the validation of the proposed methodology. The tower is a monumental medieval masterpiece, located in Perugia, Italy, and it represents a relevant case study in the scientific literature due to its important experience during the 2016-2017 seismic sequence that occurred in Central Italy. While the OMA-vibration data processing assessed distinct earthquake-induced changes in its global dynamic behavior, the focus of the present work is the results on the use of linear as well as non-linear modeling, i.e. SM and IDA, respectively, aimed for post-earthquake damage localization and quantification.
\end{abstract}

Keywords: Structural Health Monitoring, Digital Twin, Incremental Dynamic Analysis, Surrogate model, Post-earthquake damage assessment, Cultural Heritage.

ISSN:2623-3347 C 2021 The Authors. Published by Eccomas Proceedia.

Peer-review under responsibility of the organizing committee of COMPDYN 2021. doi: $10.7712 / 120121.8488 .19077$ 


\section{INTRODUCTION}

Vibration-based SHM methods based on unsupervised learning techniques have been recently demonstrated in the literature as eminently efficient for early-stage damage detection $[1,2,3,4,5,6,7,8,9,10,11,12,13]$. Due to their limitation to detection only, more advanced approaches are required in order to address higher levels of damage identification for Cultural Heritage $(\mathrm{CH})$ masonry structures.

The introduction of Digital Twin (DT) in civil engineering in the case of historic masonry constructions is a recent concept of scientific interest [14]. DT can be defined as a model or a suite of models of the structure that continuously exchanges information with the physical reality through experimental/field data, thus providing evidence of novelties or changes, for instance, related to a faulty or damage conditions.

Surrogate models (SM) have been lately investigated as computationally efficient tools to reproduce the behavior of a numerical model, potentially allowing a continuous model updating procedure for damage identification that is compatible with continuous SHM systems in historic masonry structures $[15,16,17]$. The damage localization task is performed through the inverse calibration problem on a surrogate of the linear FE model where equivalent elastic properties of macrostructural elements are considered as uncertain parameters, and by using long-term vibration data.

Other approaches are adapted given the strong development of computer processing power and advanced structural analysis software packages, aiming at more accurate analysis methods for the assessment of masonry buildings. Noteworthy to mention, non-linear dynamic analysis (NLDA) can provide a reliable assessment of the structural response of masonry constructions [18, 19, 20, 21]. In particular for NLDA, Incremental Dynamic Analysis (IDA) [22] considers the selection of time histories to be scaled at increasing seismic intensities. The application of IDA to $\mathrm{CH}$ masonry structures is comparatively less common with respect to RC structures. The recent research carried out in [21] proposed the use of an IDA-based approach for damage localization and quantification in the case of a laboratory masonry structure, but still, further investigations can be carried out in the case of full-scale historic masonry constructions.

The methodology proposed in this paper combines OMA, SM and IDA for earthquakeinduced damage identification in historic masonry towers. It is applied to the San Pietro bell tower, an iconic Cultural Heritage masonry building that was hit by the three main shocks of

the 2016 Central Italy seismic sequence: (i) Accumoli Mw6.0 earthquake of August $24^{\text {th }}$ and the following shocks, (ii) Ussita Mw5.9 earthquake of October $26^{\text {th }}$ and (iii) Norcia Mw6.5 of October $30^{\text {th }}[4,23,24]$. Fig. 1 illustrates a schematic view of the monitoring system and the FE model constructed in the ABAQUS platform [25]. With concern to the proposed methodology, the tower is ideally subdivided into three distinct structural parts: the shaft, the belfry and the cusp.

The paper is organized as follows. Section 2 describes the proposed methodology, while Section 3 reports the results and its validation. Finally, Section 4 summarizes the main conclusions of the work.

\section{METHODOLOGY}

This paper investigates a new methodology for rapid damage detection, localization and quantification in long-term monitored historic masonry towers subjected to earthquakes. It merges the data-driven OMA-based approach for a rapid and automated damage detection with two combined Digital Twins for damage localization and quantification: (i) SM-based damage 


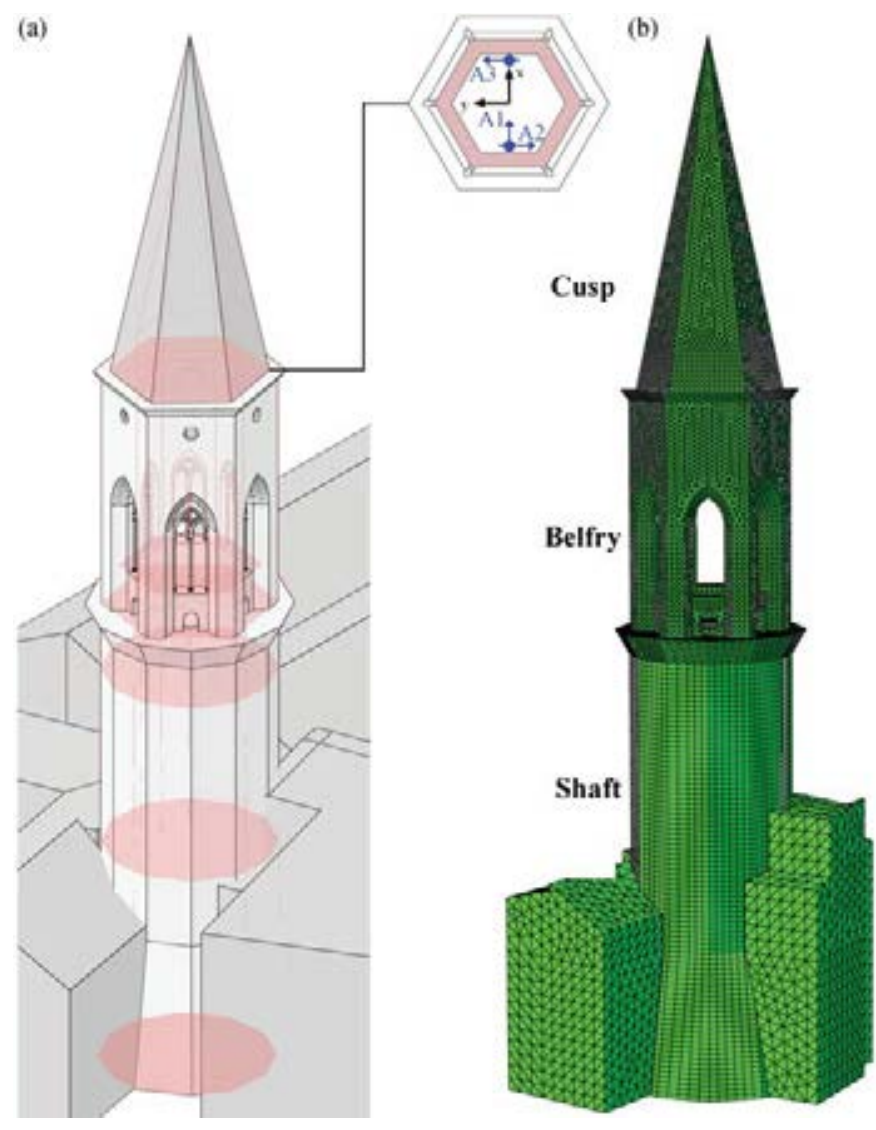

Figure 1: The monitoring system installed on the San Pietro bell tower (a) and view of the calibrated FE model (b).

identification based on linear numerical modeling and long-term vibration monitoring data and (ii) IDA-based damage identification relying on a non-linear model and seismic response to earthquakes.

The OMA is based on a Stochastic Subspace Identification (SSI) technique. Concerning the SM, among different SM models available in the literature, the Response Surface Method (RSM) has been proposed to be used here. Finally, the IDA approach investigates tensile damage $\left(d_{t}\right)$ as a Damage Measure (DM) versus significant uncorrelated Intensity Measures (IMs).

Main theoretical aspects about SM and IDA can be found in [16, 17] and [21], respectively.

\section{VALIDATION RESULTS}

The OMA-based damage detection has been applied using 5 years of vibration-based monitoring data, from December 2014 onwards. Time series of identified natural frequencies have been used for the novelty analysis. Fig. 2 illustrates the control chart where earthquake-induced damage has been identified in correspondence to the seismic events. It is clear from the plot that it represents anomalous deviations from normal conditions due to small permanent changes of the structural behavior of the bell tower, highlighted right after the Accumoli earthquake, as well as after Ussita and Norcia shocks.

The SM of the San Pietro bell tower has been constructed considering the FEM ideally subdivided into three distinctive macroelements and thus parametrized by means of a set of damagesensitive features. A training population of $N=2048$ individuals has been uniformly generated by using a Latin Hypercube Sampling (LHS) method. The design variables are represented by the stiffness multipliers $k_{i}$ of the shaft, belfry and cusp, respectively $\left(\mathrm{x}=\left[k_{1}, k_{2}, k_{3}\right]^{\mathrm{T}}\right)$. 


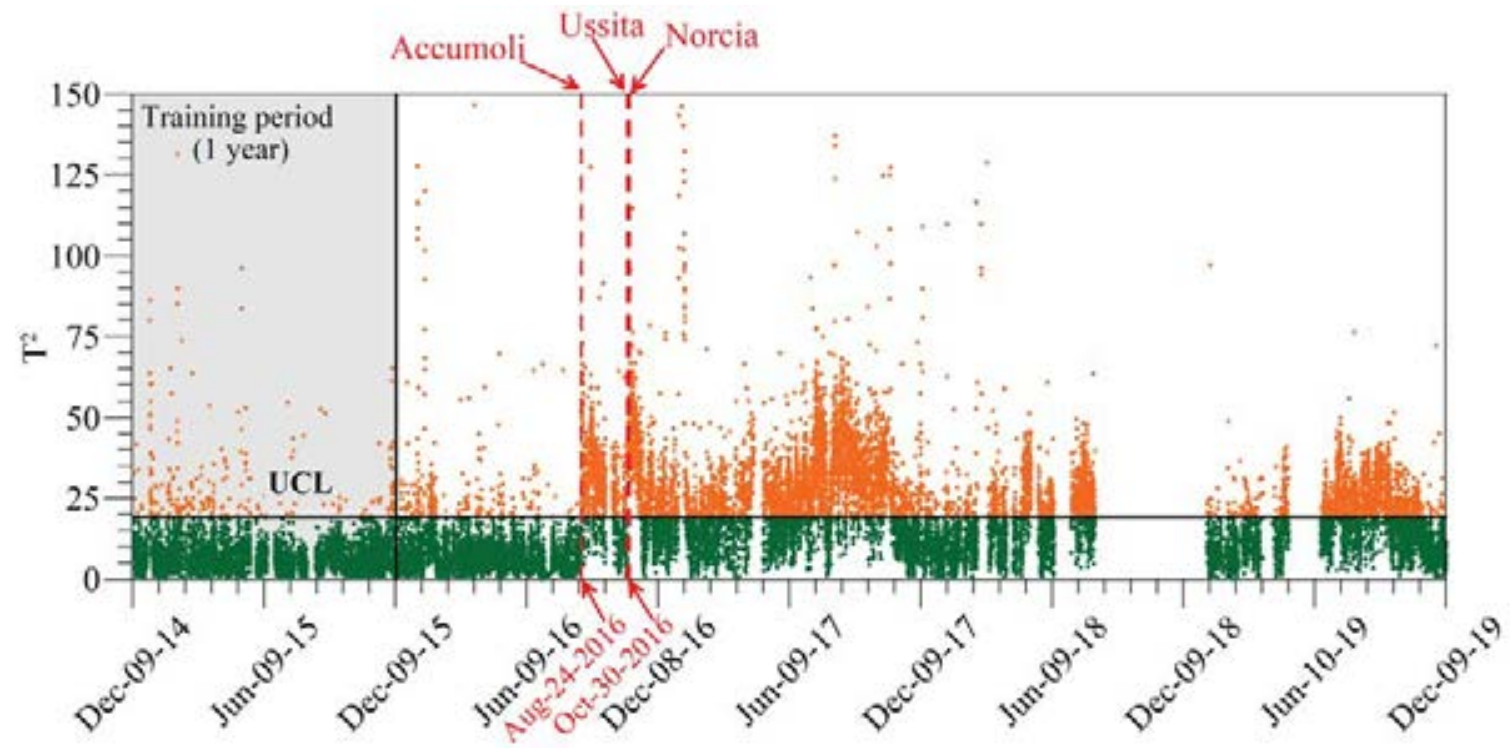

Figure 2: OMA-based damage detection: 5-year control chart with main seismic events highlighted.

Subsequently, the SM-based damage identification approach has been applied before and after the 2016 seismic sequence for localizing and quantifying earthquake-induced damage, whereby time series of cleansed natural frequencies and experimental eigenvector components have been used as input for solving the inverse FE model calibration problem on the RSM-type SM.

A first investigation on the time histories of the stiffness multipliers $k_{i}$ has been carried out, where instant decays have been quantitatively evaluated for each macroelement by comparing values identified before and after each shock. The $k_{2}$ multiplier experiences the highest variation, denoting that damage has occurred in the belfry macroelement, while the shaft and the cusp show insignificant values. Subsequently, the $k_{i}$ vectors have been independently used to build the statistical models for novelty analysis. The control charts are illustrated in Fig. 3, where the damage can be clearly localized in the belfry macroelement. The relative frequency

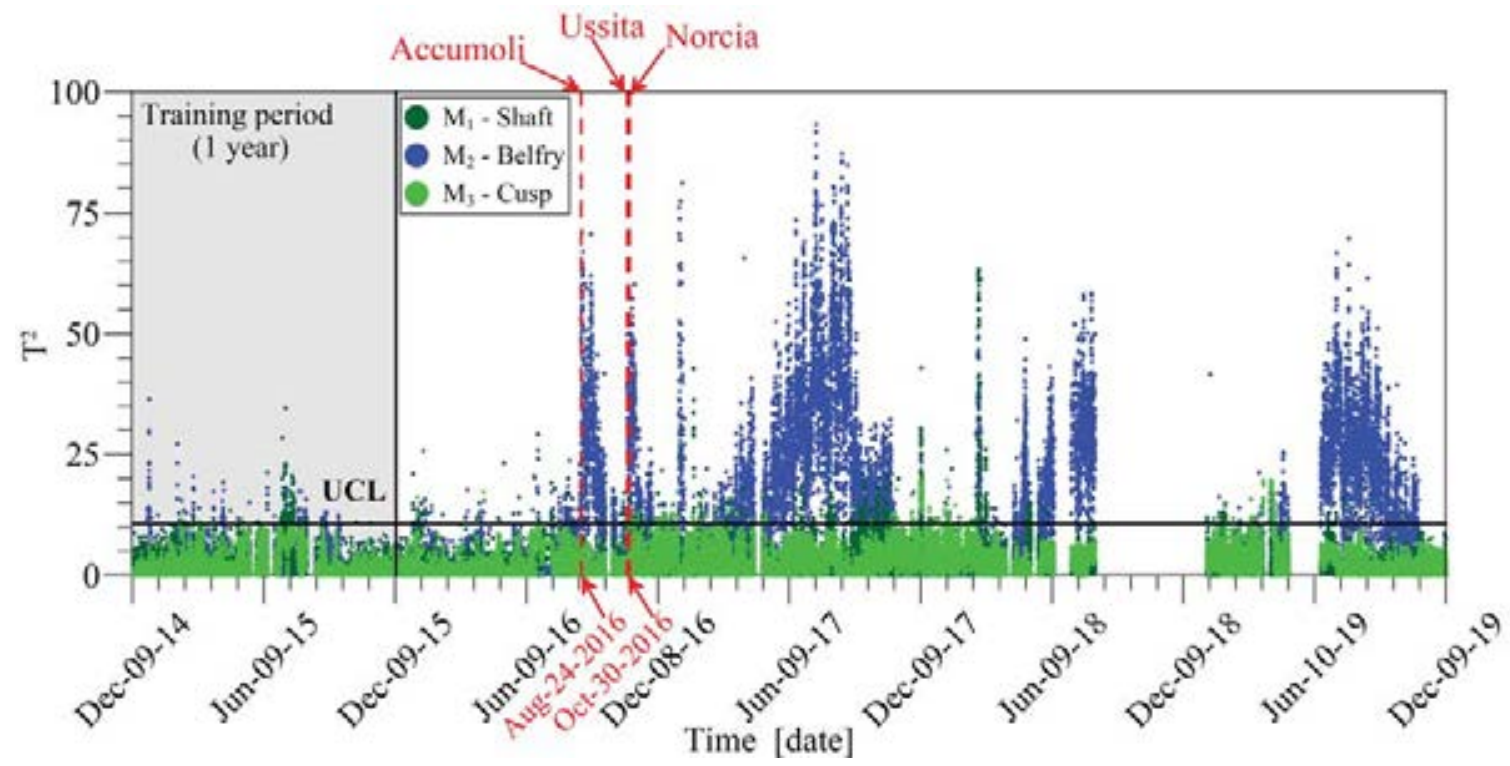

Figure 3: SM-based damage identification: 5-year control charts obtained with stiffness multipliers $k_{i}$. 
of outliers in the case of the belfry "jumps" from $2.21 \%$ before the earthquake sequence to $36.41 \%$ after the sequence, while for the shaft and the cusp it remains under $2.5 \%$.

As reported by the statistical correlation analysis carried out in [21], nineteen weakly correlated IMs have been investigated for the construction of the IDA curves, independently from the case study. These IMs have been exploited in the present paper for the San Pietro bell tower, while tensile damage $\left(d_{t}\right)$ has been used as DM (computed as a volume-averaged damage parameter). Local damage conditions have been investigated for the three distinct macroelements: shaft, belfry and cusp. Figs. 4a-b depict IDA curve sets obtained from spectral accelerations $\mathrm{S}_{\mathrm{a}}$ (T1) and Peak Ground Velocity (PGV), while other curves can be found in [24]. From the plots, the belfry can be immediately identified as the most vulnerable macroelement where the maximum numerically obtained tensile damage $d_{t}$ is equal to about 0.85 .

The recordings of the main earthquakes of the 2016 Central Italy seismic sequence have been used in the IDA-based damage identification approach. Once all the IDA curve sets have been

(a)

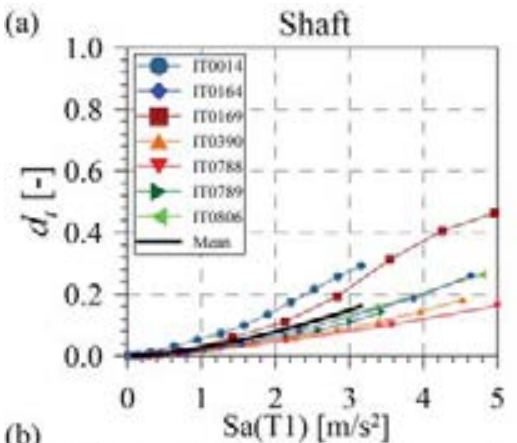

(b)

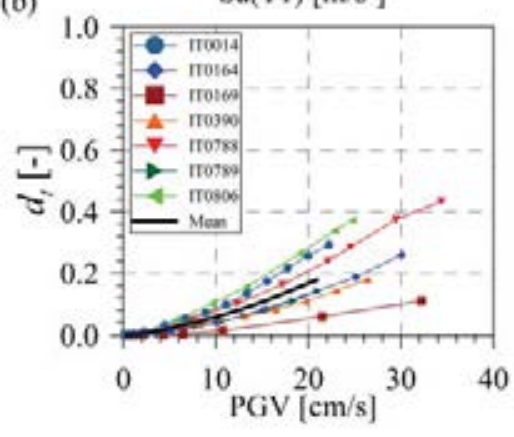

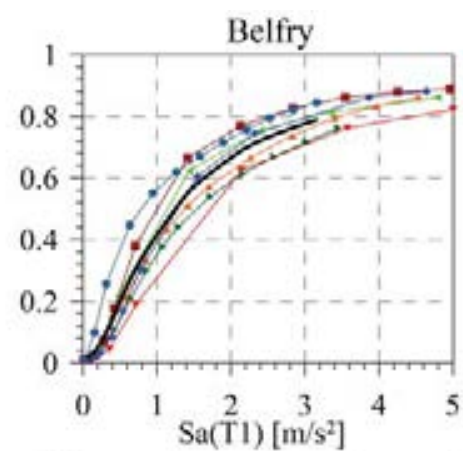

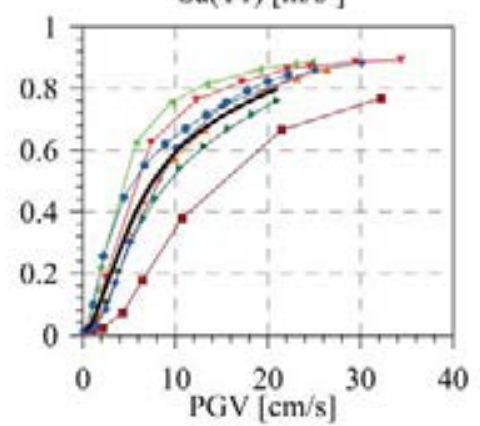

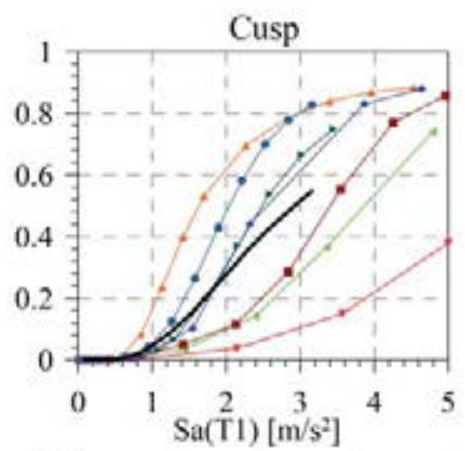

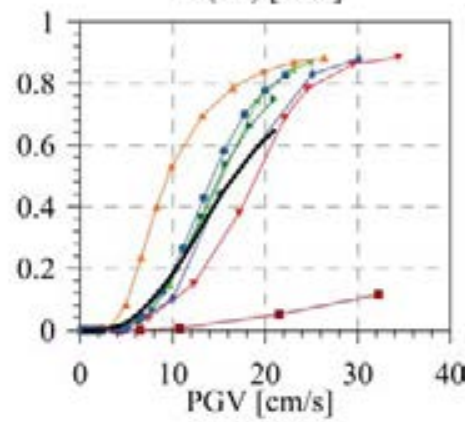

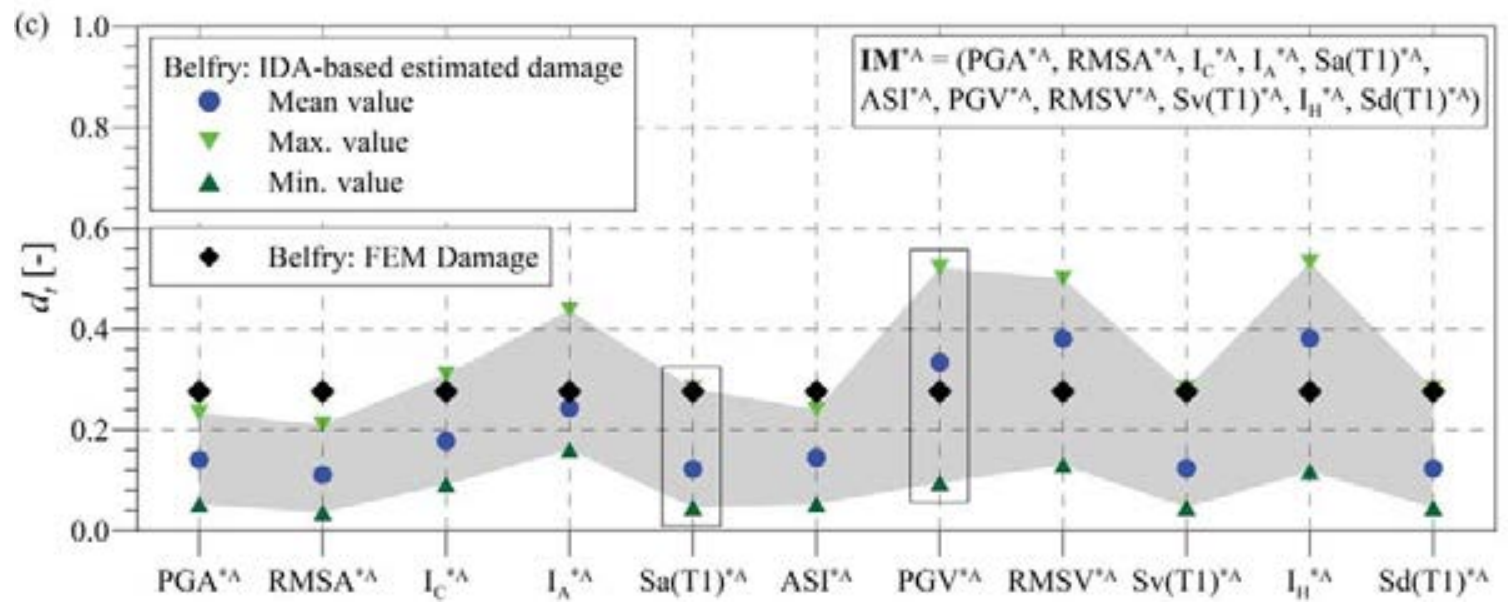

Figure 4: The IDA curve sets obtained with tensile damage, $d_{t}$, versus $\mathrm{S}_{\mathrm{a}}$ (T1) (a) and PGV (b), and IDA-based tensile damage estimated for the belfry macroelement by means of eleven input IMs calculated from Accumoli earthquake (c). 
constructed and their dispersion investigated, local damage conditions have been assessed by using seismic input and response IMs of the real aforementioned seismic events. Eleven seismic input IMs have been computed from the base seismic records and seven seismic response IMs have been calculated from the top seismic records. Fig. 4 illustrates damages estimated in the belfry macroelement by applying all eighteen IMs that are computed from Accumoli, Ussita and Norcia earthquakes, respectively. Besides IDA-based damages that are reported in terms of minimum, maximum and mean values, damage predicted through a direct non-linear FEM simulation is also reported for comparative purposes. It can be seen that there is relatively good consistency, whereby $d_{t}$ values fall within the corresponding estimated ranges.

\section{CONCLUSIONS}

The paper presented the validation results of the proposed methodology for earthquakeinduced damage identification in historic masonry towers. The San Pietro bell tower (Perugia, Italy) that was hit by the 2016 Central Italy seismic sequence has been considered as the case study.

The main concluding remarks are listed below.

- The OMA-based data-driven method is extended through the introduction and implementation of Digital Twins, in particular SM and IDA, for localization and quantification of earthquake-induced damage.

- Both SM and IDA are comparatively combined for higher accuracy of the method: (i) the former uses a linear model while the latter a non-linear one, (ii) IDA uses the recorded seismic response of an earthquake, whereas OMA and SM are based on long-term vibration monitoring data in operational conditions.

- Five years of continuous monitoring data of the San Pietro bell tower have been used in the SM-based procedure for earthquake-induced damage detection and localization and damage has been localized mainly in the belfry macroelement.

- Non-linear seismic IDA procedure has also identified the belfry as the most significantly vulnerable and damaged macroelement of the bell tower. In addition, top recorded seismic responses during earthquakes have allowed the introduction of seismic response IMs.

- Both Digital Twins have localized and consistently quantified earthquake-induced damage in the belfry macroelement.

The successful validation of the Digital Twins can result potentially useful in more severe future earthquake scenarios due to the precious information provided for needed first inspections, retrofit and strengthening interventions.

\section{ACKONWLEDGEMENTS}

The supports of the Italian Ministry of University and Research (MIUR) and the University of Perugia are acknowledged, within the Program "Dipartimenti di eccellenza 2018-2022". 


\section{REFERENCES}

[1] L.F. Ramos, L. Marques, P.B. Lourenço, G. De Roeck, A. Campos-Costa, J. Roque, Monitoring historical masonry structures with operational modal analysis: Two case studies. Mechanical Systems and Signal Processing, 24, 1291-1305, 2010.

[2] M.G. Masciotta, L.F. Ramos, P.B. Lourenço, The importance of structural monitoring as a diagnosis and control tool in the restoration process of heritage structures: A case study in Portugal. Journal of Cultural Heritage, 27, 36-47, 2017.

[3] F. Clementi, A. Pierdicca, A. Formisano, F. Catinari, S. Lenci, Numerical model upgrading of a historical masonry building damaged during the 2016 Italian earthquakes: the case study of the Podesta palace in Montelupone (Italy). Journal of Civil Structural Health Monitoring, 7, 703-717, 2017.

[4] F. Ubertini, N. Cavalagli, A. Kita, G. Comanducci, Assessment of a monumental masonry bell-tower after 2016 Central Italy seismic sequence by long-term SHM. Bulletin of Earthquake Engineering, 16, 775-801, 2018.

[5] A. Saisi, C. Gentile, A. Ruccolo, Continuous monitoring of a challenging heritage tower in Monza, Italy. Journal of Civil Structural Health Monitoring, 8, 77-90, 2018.

[6] D. Pellegrini, M. Girardi, P.B. Lourenço, M.G. Masciotta, N. Mendes, C. Padovani, L.F. Ramos, Modal analysis of historical masonry structures: Linear perturbation and software benchmarking. Construction and Building Materials, 189, 1232-1250, 2018.

[7] C. Gentile, A. Ruccolo, A. Saisi, Continuous Dynamic Monitoring to Enhance the Knowledge of a Historic Bell-Tower. International Journal of Architectural Heritage, 13, 992 $1004,2019$.

[8] A. Kita, N. Cavalagli, F. Ubertini, Temperature effects on static and dynamic behavior of Consoli Palace in Gubbio, Italy. Mechanical Systems and Signal Processing, 120, 180202, 2019.

[9] I. Venanzi, A. Kita, N. Cavalagli, L. Ierimonti, F. Ubertini, Continuous OMA for damage detection and localization in the Sciri Tower in Perugia, Italy. S.D.R. Amador, R. Brincker, E.I. Katsanos, M. L. Aenlle, P. Fernandez eds. 8th International Operational Modal Analysis Conference Proceedings (IOMAC 2019), p. 127-136, Copenhagen, Denmark, May 13-15, 2019.

[10] E. Giordano, N. Mendes, M.G. Masciotta, F. Clementi, N.H. Sadeghi, R.A. Silva, D.V. Oliveira, Expeditious damage index for arched structures based on dynamic identification testing. Construction and Building Materials, 265, 120236, 2020.

[11] A. Formisano, G. Di Lorenzo, L. Krstevska, R. Landolfo, Fem Model Calibration of Experimental Environmental Vibration Tests on Two Churches Hit by L'Aquila Earthquake. International Journal of Architectural Heritage, 15, 113-131, 2021.

[12] R. Alaggio, A. Aloisio, E. Antonacci, R. Cirella, Two-years static and dynamic monitoring of the Santa Maria di Collemaggio basilica. Construction and Building Materials, 268, $121069,2021$. 
[13] G. Standoli, E. Giordano, G. Milani, F. Clementi, Model Updating of Historical Belfries Based on Oma Identification Techniques. International Journal of Architectural Heritage, 15, 132-156, 2021.

[14] G. Angjeliu, D. Coronelli, G. Cardani, Development of the simulation model for Digital Twin applications in historical masonry buildings: The integration between numerical and experimental reality. Computers and Structures, 238, 106282, 2020.

[15] A. Cabboi, C. Gentile, A. Saisi, From continuous vibration monitoring to FEM-based damage assessment: Application on a stone-masonry tower. Construction and Building Materials, 156, 252-265, 2017.

[16] I. Venanzi, A. Kita, N. Cavalagli, L. Ierimonti, F. Ubertini, Earthquake-induced damage localization in an historic masonry tower through long-term dynamic monitoring and FE model calibration. Bulletin of Earthquake Engineering, 18, 2247-2274, 2020.

[17] E. Garcia-Macías, I. Venanzi, F. Ubertini, Metamodel-based pattern recognition approach for real-time identification of earthquake-induced damage in historic masonry structures. Automation in Construction, 120, 103389, 2020.

[18] P. Zampieri, M.A. Zanini, F. Faleschini, L. Hofer, C. Pellegrino, Failure analysis of masonry arch bridges subject to local pier scour. Engineering Failure Analysis, 79, 371-384, 2017.

[19] C.F. Manzini, G. Magenes, A. Penna, F. da Porto, D. Camilletti, S. Cattari, S. Lagomarsino, Masonry Italian Code-Conforming Buildings. Part 1: Case Studies and Design Methods. Journal of Earthquake Engineering, 22, 54-73, 2018.

[20] G. Karanikoloudis, P.B. Lourenço, Structural assessment and seismic vulnerability of earthen historic structures. Application of sophisticated numerical and simple analytical models. Engineering Structures, 160, 488-509, 2018.

[21] A. Kita, N. Cavalagli, M.G. Masciotta, P.B. Lourenço, F. Ubertini, Rapid post-earthquake damage localization and quantification in masonry structures through multidimensional non-linear seismic IDA. Engineering Structures, 219, 110841, 2020.

[22] D. Vamvatsikos, N.A. Cornell, Incremantal dynamic Analysis. Earthquake Engineering and Structural Dynamics, 31, 491-514, 2002.

[23] P.F. Giordano, F. Ubertini, N. Cavalagli, A. Kita, M.G. Masciotta, Four years of structural health monitoring of the San Pietro bell tower in Perugia, Italy: Two years before the earthquake versus two years after. International Journal of Masonry Research and Innovation, $\mathbf{5}, 445-467,2020$.

[24] A. Kita, N. Cavalagli, I. Venanzi, L. Ierimonti, F. Ubertini, Earthquake-Induced Damage Localization and Quantification in Historic Masonry Towers Using OMA and IDA. Lecture Notes in Civil Engineering, European Workshop on Structural Health Monitoring Proceedings (EWSHM 2020), 127, 958-967, 2021.

[25] Simulia, Corp, Abaqus Analysis User's and theory Manual. Version 6. Dessault Systemes, USA, 2019. 